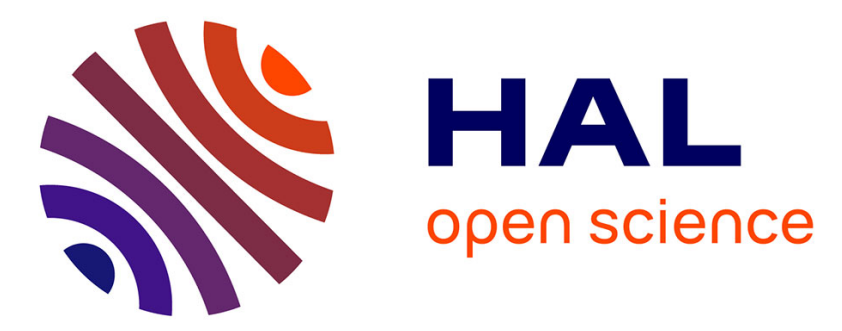

\title{
High-Fidelity Multiphysics Simulation of a Confined Premixed Swirling Flame Combining Large-Eddy Simulation, Wall Heat Conduction and Radiative Energy Transfer
}

Chai Koren, Ronan Vicquelin, Olivier Gicquel

\section{To cite this version:}

Chai Koren, Ronan Vicquelin, Olivier Gicquel. High-Fidelity Multiphysics Simulation of a Confined Premixed Swirling Flame Combining Large-Eddy Simulation, Wall Heat Conduction and Radiative Energy Transfer. ASME Turbo Expo 2017: Turbomachinery Technical Conference and Exposition, Jun 2017, Charlotte, North Carolina, United States. 10.1115/GT2017-64844 . hal-01781003

\section{HAL Id: hal-01781003 \\ https://hal.science/hal-01781003}

Submitted on 28 Apr 2018

HAL is a multi-disciplinary open access archive for the deposit and dissemination of scientific research documents, whether they are published or not. The documents may come from teaching and research institutions in France or abroad, or from public or private research centers.
L'archive ouverte pluridisciplinaire HAL, est destinée au dépôt et à la diffusion de documents scientifiques de niveau recherche, publiés ou non, émanant des établissements d'enseignement et de recherche français ou étrangers, des laboratoires publics ou privés. 


\title{
HIGH-FIDELITY MULTIPHYSICS SIMULATION OF A CONFINED PREMIXED SWIRLING FLAME COMBINING LARGE-EDDY SIMULATION, WALL HEAT CONDUCTION AND RADIATIVE ENERGY TRANSFER
}

\author{
Chai KOREN ${ }^{\ddagger}$, Ronan VICQUELIN ${ }^{\S *}$, Olivier GICQUEL $\$$ \\ $\S$ Laboratoire EM2C, CNRS \\ CentraleSupélec \\ Université Paris-Saclay \\ Grande Voie des Vignes, 92295 \\ Chatenay-Malabry cedex, France \\ \#ir Liquide \\ Centre de Recherche Paris-Saclay \\ 1 Chemin de la Porte des Loges, 78350 \\ Les-Loges-en-Josas, France
}

\begin{abstract}
A multi-physics simulation combining large-eddy simulation, conjugate heat transfer and radiative heat transfer is used to predict the wall temperature field of a confined premixed swirling flame operating under atmospheric pressure. The combustion model accounts for the effect of enthalpy defect on the flame structure whose stabilization is here sensitive to the wall heat losses. The conjugate heat transfer is accounted for by solving the heat conduction within the combustor walls and with the Hybrid-Cell Neumann-Dirichlet coupling method, enabling to dynamically adapt the coupling period. The exact radiative heat transfer equation is solved with an advanced Monte Carlo method with a local control of the statistical error. The coupled simulation is carried out with or without accounting for radiation. Excellent results for the wall temperature are achieved by the fully coupled simulation which are then further analyzed in terms of radiative effects, global energy budget and fluctuations of wall heat flux and temperature.
\end{abstract}

\section{NOMENCLATURE}

$c_{p}$ Thermal capacity at constant pressure $[\mathrm{J} / \mathrm{kg} / \mathrm{K}]$

\footnotetext{
*Address all correspondence to this author: ronan.vicquelin@centralesupelec.fr.
}

$h$ Heat transfer coefficient $\left[\mathrm{W} / \mathrm{m}^{2} / \mathrm{K}\right]$

$H$ Combustor's height [m]

$P^{\text {rad }}$ Radiative power $\left[\mathrm{W} / \mathrm{m}^{3}\right]$

$T$ Temperature [K]

$U$ Velocity component $[\mathrm{m} / \mathrm{s}]$

$V \quad$ Cell volume $\left[\mathrm{m}^{3}\right]$

$\Delta t \quad$ Time step size [s]

$\Delta x \quad$ Cell size $[\mathrm{m}]$

$\eta \quad$ Numerical tolerance [-]

$\lambda$ Thermal conductivity $[\mathrm{W} / \mathrm{m} / \mathrm{K}]$

$\phi \quad$ Heat flux $\left[\mathrm{W} / \mathrm{m}^{2}\right]$

$\Phi \quad$ Face-integrated flux [W]

$\rho$ Density $\left[\mathrm{kg} / \mathrm{m}^{3}\right]$

$\varepsilon \quad$ Wall emissivity or estimation of numerical error [-]

$(\ldots)_{f}$ Fluid domain value

$(\ldots)_{b n d}$ Boundary value

$(\ldots)_{c p l}$ Coupling value

(...) ext External conditions

$(\ldots)_{\text {rad }}$ Radiative value

$(\ldots)_{s}$ Solid domain value

$\widehat{(\ldots)}$ Numerical estimation of mean value

$(\ldots)^{\prime} \quad$ Fluctuating contribution

$(\ldots)^{\text {est }}$ Estimated value 
CASE-FW Coupled simulation accounted for reactive flow and wall heat transfer

CASE-FWR Coupled simulation accounted for reactive flow, wall heat transfer and radiation

CHT Conjugate Heat Transfer

DNS Direct Numerical Simulation

HCND Hybrid-Cell Neumann-Dirichlet

LES Large Eddy Simulation

RANS Reynolds-Averaged Navier-Stokes

RMS Root Mean Square value

TRI Turbulence-Radiation Interaction

\section{INTRODUCTION}

The increasing number of applications of large-eddy simulations (LES) in practical combustor configurations $[1,2]$ outlines the growing maturity of such methods to simulate turbulent reactive flows. While subgrid-scale modeling efforts are still ongoing, the range of applications of such high-fidelity computations widens to new horizons such as multiphysics simulations of conjugate heat transfer (CHT). Several applications to turbine blades have been reported [3,4] as well as combustion cases [5-7]. The accurate prediction of heat flux and temperature at the combustor wall requires accounting for the coupling between the turbulent reactive flow, the heat conduction within the walls and the radiative energy transfer. The later phenomenon, radiation, has also been coupled to reactive LES in different studies [6,8-10]. Combining LES with conjugate heat transfer and thermal radiation in a multiphysics framework can nowadays be envisioned and enables a state-of-the-art estimation of wall heat loads. Besides, coupling LES with radiative heat transfer enables to alleviate the issue of Turbulence-Radiation Interaction (TRI) [11,12] which is significant in RANS simulations. While being neglected here, subgrid-scale TRI effects are strictly not negligible and modeling studies have recently emerged $[13,14]$. Finally, accurate unsteady simulations such as LES to predict unsteady wall heat loads is very promising to determine thermal fatigue in combustors as recently developed in the nuclear engineering community [15-17].

A multiphysics simulation is here applied to a confined premixed swirling flame $[18,19]$ whose stabilization has been shown to be sensitive to the wall conditions as in other similar flames [20-23]. The flame has previously been simulated successfully in a non-coupled and stand-alone LES based on a non-adiabatic F-TACLES (Filtered Tabulated Chemistry for LES) model [24]. The wall temperature profiles were then specified from the experimental ones that were measured by Laser Induced Phosphorescence. The objective of this study is to predict this wall temperature field in order to retrieve the combustor characteristics in terms of flame stabilization and wall heat losses without any prior knowledge from the experimental data.
The proposed multiphysics simulation relies on separate solvers to treat each physical phenomenon as accurate as possible. A similar and pioneering high-fidelity approach has been presented in [6] and applied a helicopter combustor while describing the radiation properties with a global model. The coupling frequency with the radiation solver was however strongly limited. Regarding the retained approach in the present study, the large-eddy simulation benefits from the continuous advances in combustion modeling [25], in particular on the effect of variable enthalpy due to heat losses on the flame structure and its stabilization [24, 26-28]. The conjugate heat transfer is accounted for by solving the heat conduction within the combustor walls. This heat transfer solver is coupled to the LES with the recently developed Hybrid-Cell Neumann-Dirichlet coupling method [29]. It enables i) to carry out coupled simulations while controlling the coupling period from a user-specified accuracy tolerance and ii) to access the permanent regime statistics at the combustor walls through an acceleration method [30] which skips the slow transient heating of the chamber without modifying the level of fluctuations in wall temperature and heat flux. The radiative heat transfer equation is solved with an Optimized Emission-based Reciprocal Monte-Carlo method [31] while accounting for detailed gas spectral radiative properties. While being computationally intensive, such a Monte Carlo solver with a local control of the statistical error provides very accurate results. The obtained level of accuracy of the proposed coupled multiphysics simulation of realistic configurations yields a highfidelity method beyond the state of the art.

The first section details the numerical solvers and their coupling procedure. Coupled simulations are then carried out on the investigated confined premixed swirling flame with or without accounting for radiative energy transfer. Results are compared to experimentally measured wall temperature before being further analyzed in terms of global energy budget and fluctuations of wall heat flux and temperature.

\section{EXPERIMENTAL AND NUMERICAL SETUPS Experimental setup}

The experimental setup was studied experimentally by Guiberti et al. [19,24]. A schematic view of the setup is available in Fig. 1. The combustion chamber height $H$ is $250 \mathrm{~mm}$ with a square cross-section. It encloses of a swirled premixed flame, where the fuel is a mixture of $\mathrm{H}_{2}$ and $\mathrm{CH}_{4}(60 \%$ and $40 \%$ in volume, respectively). The equivalence ratio is 0.7 , the swirl number is set to 0.4 and the fresh gases temperature is $293 \mathrm{~K}$. The corresponding thermal power of the flame is $4 \mathrm{~kW}$.

The numerical setup and modeling of the reactive flow, described in the next section, has previously been validated [24] against measurements of velocity profiles, $\mathrm{OH}^{*}$ chemiluminescence and OH-PLIF. Wall temperature measurements determined by Laser Induced Phosphorescence which were then prescribed 


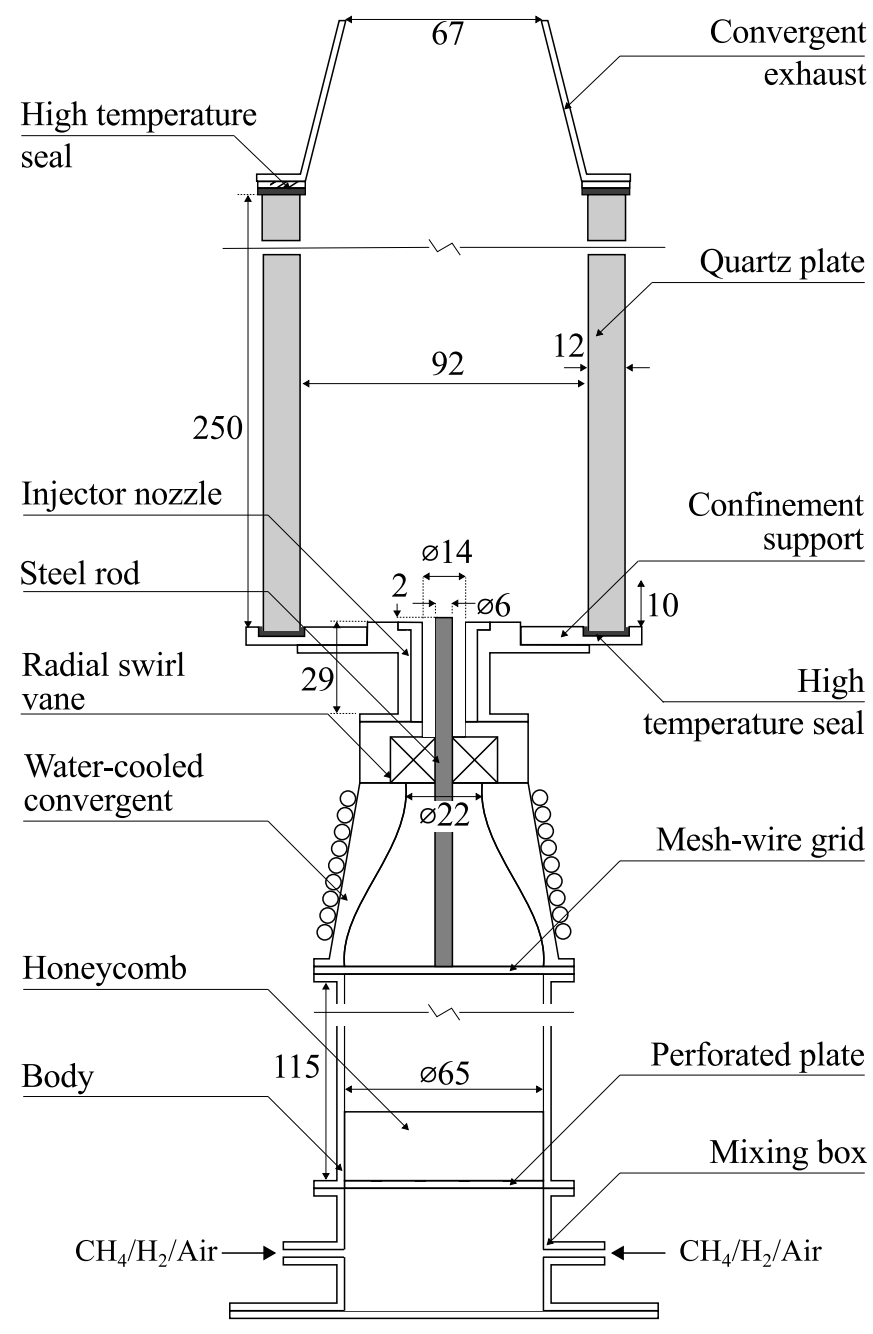

FIGURE 1. Schematic view of the studied burner [18, 19,24].

as boundary conditions in the simulation are here the target data to be predicted by a multi-physics approach . Such data are available for one of the four combustor's quartz windows in a $51 \mathrm{~mm}$ $\mathrm{x} 58 \mathrm{~mm}$ zone.

\section{Numerical solvers}

The multi-physics simulation is carried out by coupling separate solvers that describe the turbulent reactive flow, radiative heat transfer and wall heat transfer. The three solvers are detailed below.

Turbulent reactive flow The retained setup for largeeddy simulation of reactive flows is identical to [24]. The YALES2 LES solver [32,33] is based on a low Mach-number assumption and uses finite-volume formalism with fourth order time integration and space discretization schemes. The pressure Poisson equation is solved using a deflated conjugate gradient method [33].

The chemistry and turbulent combustion are described with the tabulated chemistry model F-TACLES $[34,35]$ and Charlette et al. [36] subgrid-scale flame wrinkling model. For the considered configuration which features heat losses, the effect of enthalpy variations on the combustion model is accounted for with a non-adiabatic extension $[28,37]$ of the F-TACLES model. For perfectly-premixed conditions as studied here, the different physical variables are only tabulated as a function of a progress variable $Y_{c}$ and a heat losses correction coefficient [28].

A first stand-alone LES was conducted using wall laws to account for unresolved boundary layers. It showed a maximal value of cell size in wall units $y^{+} \approx 1.5$ (similar in terms of $x^{+}$ and $z^{+}$). The retained grid is then fine enough for the investigated case and enables a wall-resolved LES where no wall-modeling is required.

Gases radiation The burnt gases thermal radiation is accounted fo by solving the radiative transfer equation without taking into subgrid turbulence-radiation interaction. This is done with a Monte-Carlo method implemented in the RAINIER solver, an in-house parallel code of the EM2C laboratory. Such methods are deemed the most accurate after deterministic ray tracing. They can account for complex geometries and spectral properties. Here, a $\mathrm{cK}$ method based on accurate parameters directly obtained from a high-resolution database [38] enables a detailed description of radiative properties of $\mathrm{CO}_{2}$ and $\mathrm{H}_{2} \mathrm{O}$. In order to afford coupling such Monte-Carlo methods with LES, several features must be met: parallel scalability, local accuracy control and fast convergence. The RAINIER code uses an Optimized Emission-based Reciprocity Monte-Carlo method (OERM) [31]. Scalability is strongly enhanced by treating each mesh point independently from the others with a local monitoring of the statistical error. Such a property is inherited by the ERM approach [39]. ERM is however penalized by a slow statistical convergence in cold absorbing regions. This limitation is overcome by OERM using a frequency distribution function based on the emission distribution at the maximum temperature encountered in the system. Thanks to the RAINIER solver, studies of accurate radiative energy transfer in DNS or LES have become affordable recently [40-42]. In the present study, the local control of the Monte-Carlo convergence is set such that the results' standard deviation is either below $10 \%$ or, for points with small radiative contributions, below $3 \%$ of he maximum radiative power value. Additionally, fixing an upper threshold for the total number of rays per points allows not to spend computational efforts in irrelevant points such as those with negligible contribution to the radiative energy transfer. After carrying out several standalone radiation computations to determine this threshold, a 
maximum number of 4,000 rays per point was determined to allow matching of the convergence criteria for $99.9 \%$ of the points.

Wall heat transfer solver Conjugate heat transfer is taken into account by solving the heat conduction within the solid parts of the combustion chamber. Only the four quartz windows that constitute the chamber walls are here discretized. The temperature of the bottom wall that corresponds to the swirled injection exit plane is fixed in the reactive flow simulation from thermocouple measurements. The physical properties of the quartz (type GE-124) are taken as $c_{p_{s}}=954 \mathrm{~J} / \mathrm{kg} / \mathrm{K}, \rho_{s}=2200 \mathrm{~kg} / \mathrm{m}^{3}$ and $\lambda_{s}=1.52 \mathrm{~W} / \mathrm{m} / \mathrm{K}$. The windows dimensions are: $250 \mathrm{~mm}$ (height) x $92 \mathrm{~mm}$ (width) x $12 \mathrm{~mm}$ (thickness).

As explained in the section about the coupling procedure, two heat transfer solvers are used: the first one solving the unsteady heat equation, the second one solving the steady heat equation. Let us outline that both are actually instances of the YALES2 library and hence share the same data structure and discretization schemes as the flow solver: The unsteady heat transfer solver is then a finite volume solver using fourth-order schemes for space discretization and explicit time integration; Regarding the steady heat transfer solver, the linear system obtained by fourth-order spatial discretization of the steady heat equation is solved with the same parallel algorithm [33] as for the pressure Poisson equation.

Boundary conditions for quartz walls are provided on the internal side coupled with the reactive flow solver following the coupling procedure (see next section) and on the external side in contact with ambient air at the temperature $T_{\text {ext }}=293 \mathrm{~K}$. The contribution from the external free convection boundary layer begin rather moderate, one must not forget the radiative flux on the external side. Given the hot wall temperature, the radiative heat flux cannot be linearized. The expression of the external wall heat flux $\phi_{b n d}^{e x t}$ provides then a mixed boundary condition accounting for both free convection and radiative transfer,

$$
\phi_{b n d}^{e x t}=h_{\text {ext }}\left(T_{b n d}-T_{\text {ext }}\right)+\varepsilon_{\text {bnd }} \sigma\left(T_{b n d}^{4}-T_{\text {ext }}^{4}\right)
$$

where natural convection is described by the heat transfer coefficient $h_{\text {ext }}(z), \varepsilon_{\text {bnd }}=0.75$ is the wall emissivity, and $\sigma$ is the Stefan-Boltzmann constant. Given the laminar regime of the external free-convection boundary layer, $h_{\text {ext }}(z)$ is given by the Nusselt number expressed as $\mathrm{Nu}(z)=0.39 \mathrm{Ra}^{1 / 4}$ with the Rayleigh number Ra. Accounting for the 2-cm-wide plate below the quartz windows, an origin $z_{0}=2 \mathrm{~cm}$ is introduced such that

$$
h_{\text {ext }}(z)=\frac{\mathrm{Nu}\left(z-z_{0}\right) \lambda_{\text {air }}}{z-z_{0}} .
$$

Air properties used to compute $\lambda_{\text {air }}$ and the Rayleigh number are taken at a film temperature $T_{m}=0.5\left(T_{e x t}+T_{b n d}\right)$. The sensitivity to the value of $h_{\text {ext }}(z)$ determined by Eq. 2 is studied in a simple manner by considering a 1D $12 \mathrm{~mm}$-thick quartz layer with an imposed heat flux on the inner side $\left(\phi_{0}=3.5 \mathrm{~kW} / \mathrm{m}^{2}\right)$. The outer boundary condition used is the one prescribed by Eq. 2 for different values of the convective heat coefficient $h_{\text {ext }}$. As it can be seen in Fig. 2 , modifying $h_{\text {ext }}$ by $10 \%$ only causes a $1 \%$ variation in the inner wall temperature. Hence, the influence of the external convective heat coefficient on the wall temperature is small.

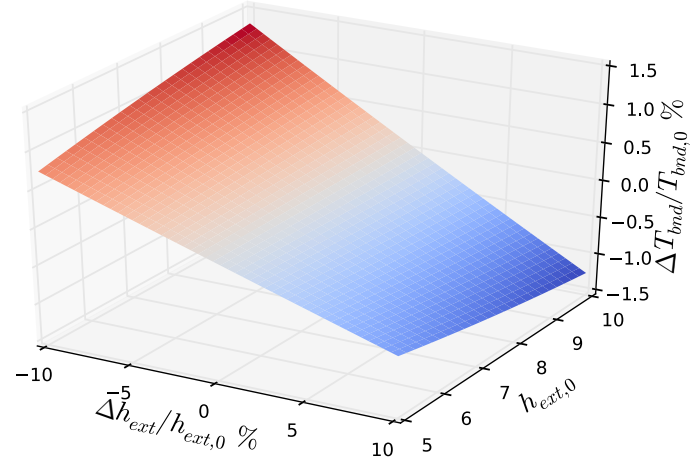

FIGURE 2. Result of the 1D parametric study to quantify the sensitivity to the $h_{\text {ext }}$ value: Surface plot of the resulting relative variation in the inner wall temperature $T_{b n d}$ as a function to a reference value $h_{\text {ext }, 0}$ and its relative variation.

For the linear steady heat transfer solver, the resolution must be adapted to the non-linear boundary condition in Eq. 1 . An outer iterative method (Fig. 3) with a fixed point algorithm is used on the external boundary temperature field. Within each outer iteration, the linear steady solver is applied to the linearized system where the radiative component is written as $T_{b n d}^{4} \approx T_{b n d} \cdot\left(T_{b n d}^{e s t}\right)^{3}$ to provide a new value for $T_{b n d} . T_{b n d}^{e s t}$ is an estimation of the converged value of the external wall temperature which is updated after each iteration. This is repeated until the convergence is reached for the external boundary temperature field, which corresponds to the solution of the original non-linear heat transfer problem. Considering the solution converged when the variations between outer iterations are less than $5 \%$ yields an average number of five outer iterations in the studied case.

\section{Coupling procedure}

Multi-physics simulations are carried out by coupling the aforementioned solvers. The coupling between the reactive LES and wall heat transfer solvers, which enables simulations of conjugate heat transfer, is first detailed. The additional coupling 


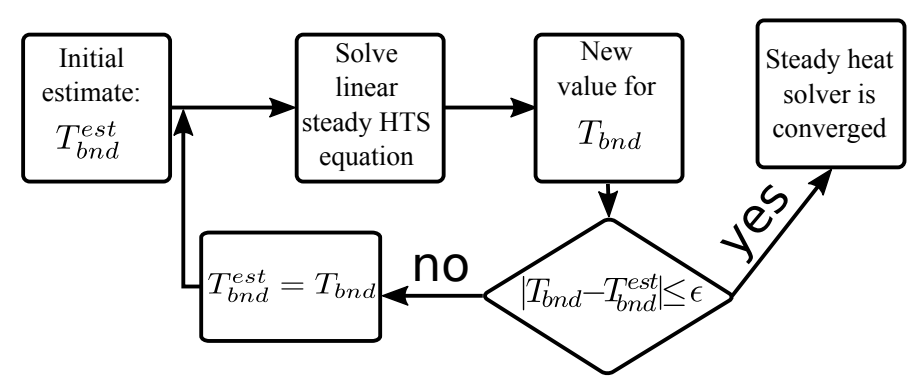

FIGURE 3. Control loop for the fixed point algorithm used to solve the steady heat transfer equation when a radiative boundary condition is applied.

with radiative energy transfer is then described. All exchanged data between solvers are communicated with the coupling library OpenPALM [43] developed specifically for massively parallel coupled simulations.

Coupling reactive LES and wall heat transfer The heat transfer solver is coupled to the LES with the recently developed Hybrid-Cell Neumann-Dirichlet (HCND) coupling method [29]. It enables to carry out coupled simulations while controlling the coupling period from a user-specified accuracy tolerance. Such a procedure allows a control of the accuracy of unsteady conjugate heat transfer simulations, which is particularly suited for high-fidelity simulations of CHT with DNS or LES. However, when studying the permanent regime statistics, simulating accurately the transient heating of the combustor's walls is unaffordable with LES given the slow conduction process in the solid parts. An acceleration technique is then applied to skip to the permanent regime. An accelerated HCND has been derived and validated [30], the corresponding coupling procedure is here briefly described.

The acceleration is achieved by considering the superposition of unsteady and steady components for all quantities in the solid walls or at their boundary. For example, the solid temperature is written as $T_{s}=\widehat{T}_{s}+T_{s}^{\prime}$. The steady temperature in the solid domain is then evaluated, after each coupling iteration, by the steady heat transfer solver with the external boundary condition in Eq. 1 and the internal Neumann boundary condition prescribed by the current value of the mean wall conductive flux computed on the reactive-flow side.

The coupling procedure to estimate the unsteady conjugate heat transfer considers a layer of hybrid-cells at the flow-wall interface (see Fig. 4). The corresponding evolution of the unsteady part of the boundary temperature is written as

$$
\frac{d T_{b n d}^{\prime}}{d t}=-\frac{\Phi_{f, b n d}^{\prime}+\Phi_{s, b n d}^{\prime}}{V_{f} \rho_{f} c_{p f}+V_{s} \rho_{s} c_{p s}}
$$

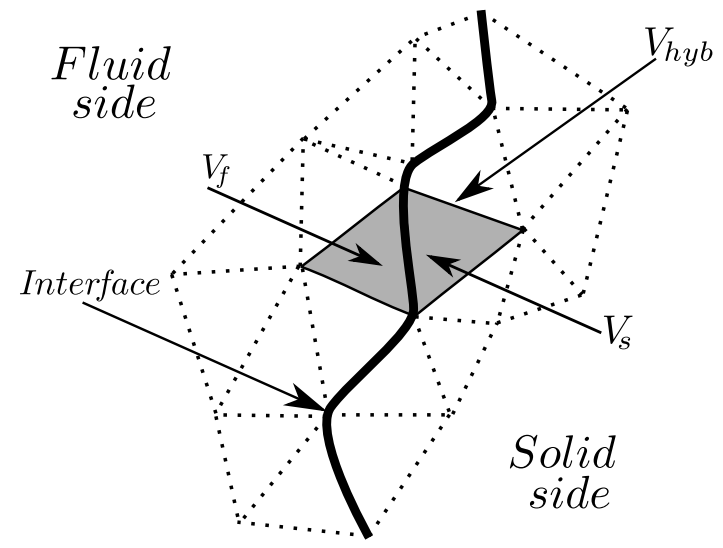

FIGURE 4. One hydrib cell of volume $V_{h y b}$ (in grey) is the union of fluid and solid cells of volume $V_{f}$ and $V_{s}$ located on each side of the interface.

The unsteady contributions of heat fluxes $\Phi_{f, \text { bnd }}^{\prime}$ and $\Phi_{s, b n d}^{\prime}$, are provided by both flow and unsteady heat transfer solvers. Equation 3 is solved after each coupling iteration with a time-step control algorithm which allows the dynamic determination of the coupling time step given an accuracy tolerance. Once the temperature at the flow-wall interface has been updated, it is used as Dirichlet boundary conditions for both flow and unsteady heat transfer solvers during their respective time integration between two coupling steps. Considering a 1D domain and a fixed coupling time step $\Delta t_{c p l}$, one can characterize the stability of coupling procedure [29] in terms of an hybrid Fourier number,

$$
\mathscr{F}_{h y b}=\frac{\Delta t_{c p l}}{\rho_{f} c_{p f} \Delta x_{f}+\rho_{s} c_{p s} \Delta x_{s}}\left(\frac{\lambda_{f}}{\Delta x_{f}}+\frac{\lambda_{s}}{\Delta x_{s}}\right) .
$$

Given the retained explicit time integration of Eq. 3, the critical stability value of $\mathscr{F}_{h y b}$ (function of several parameters) is of the order of unity. Despite such a value is impractical for studies of steady CHT using RANS where very large time steps are considered, this is not an issue in LES. Indeed, LES is here used to i) compute mean wall temperature and heat flux with an acceleration method and ii) to capture unsteady heat loads from the turbulent flow. The accurate temporal resolution of such unsteadiness is handled by the coupling time step adaptation algorithm based on a prescribed accuracy threshold [29]. This accuracy requirement typically results in a coupling time step below the stability limit. Let us note that the PID time-step controller would prevent the time step to go beyond the stability limit anyway.

The unsteady heat transfer solver determines the unsteady part of the solid domain temperature given by

$$
\rho_{s} c_{p, s} \frac{\partial T_{s}^{\prime}}{\partial t}=\nabla \cdot\left(\lambda_{s} \nabla T_{s}^{\prime}\right) .
$$


The described accelerated HCND coupling method has been shown [30] to compute accurately steady state fields without perturbing the unsteady contributions whose accuracy is controlled with a self-adaptive coupling period.

Coupling with radiation The radiative energy transfer from burnt gases and the combustor walls (internal side) is accounted for by coupling the Monte-Carlo solver to the reactive flow solver. The latter provides the former with the gaseous mixture composition, gases and wall temperature fields. The MonteCarlo solver then returns the volume radiative power which is used as a local source term in the gaseous enthalpy equation, and the wall radiative flux $\Phi_{\text {rad,bnd }}$ which is added to the heat flux $\Phi_{f, b n d}$ whose contributions are sent to the boundary temperature solver and the steady heat transfer solver. The communication scheme between solvers is presented in Fig. 5. To be

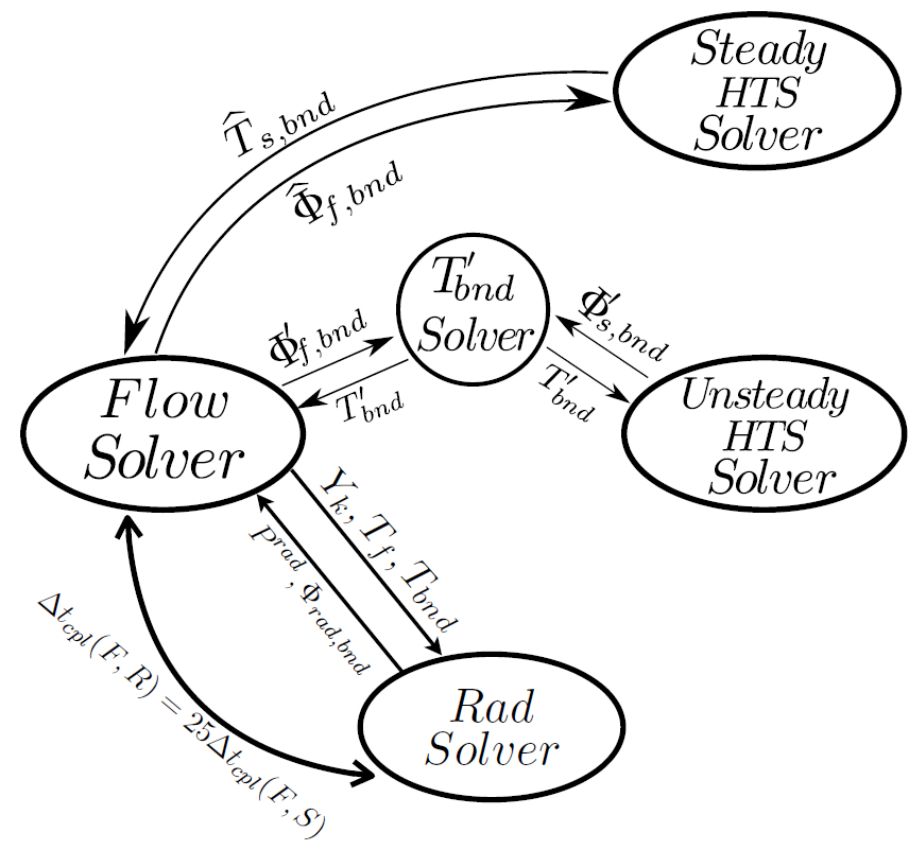

FIGURE 5. Communication scheme of exchanged data for the coupling between the radiative transfer solver, the reactive flow solver and the wall heat transfer solvers

affordable with the available computational ressources, the radiative transfer equation is solved on a coarser mesh compared to the flow solver. The interpolation between meshes is handled by the OpenPalm coupling library. A dynamic coupling adaptation as not been derived yet for multi-physics simulations with radiation. The reactive flow and radiative transfer codes are then coupled with a fixed coupling time step, $\Delta t_{c p l}(F, R)$, related to
TABLE 1. Mesh size (in millions of cells) and number of cores used by each code for both the flow-wall coupled case and the flow-wallradiation coupled case.

\begin{tabular}{ccccc}
\hline & \multicolumn{2}{c}{ CASE-FW } & \multicolumn{2}{c}{ CASE-FWR } \\
& Mesh size & \#CPUs & Mesh size & \#CPUs \\
\hline Reactive LES & $49 \mathrm{M}$ & 960 & $49 \mathrm{M}$ & 256 \\
\hline Wall heat transfer & $41 \mathrm{M}$ & 95 & $41 \mathrm{M}$ & 96 \\
\hline Radiation & - & - & $8 \mathrm{M}$ & 991 \\
\hline
\end{tabular}

the flow-wall coupling time $\Delta t_{c p l}(F, S)$ such that $\Delta t_{c p l}(F, R)=$ $25 \Delta t_{c p l}(F, S)$.

\section{RESULTS AND DISCUSSION}

The combination of i) large-eddy simulation with a combustion model that accounts for the effect of enthalpy defect on the flame structure, ii) an efficient Monte-Carlo solver with detailed radiative properties and controlled accuracy, and iii) a self-adaptive coupling procedure for conjugate heat transfer to compute accurately steady and unsteady components of the solid domain temperature, provides a high-fidelity coupled simulation which, to the best of the authors knowledge, is unprecedented in the investigated realistic configuration.

Results are presented for two coupled simulations: The first one considers coupled effects between the reactive flow and the walls heat transfer (denoted as CASE-FW), while the second additionally accounts for radiation (denoted as CASE-FWR). Let us outline once again that the numerical (discretization scheme and mesh) and modeling (subgrid and combustion model) setup of the LES solver is identical to the one in [24]. In this previous study, the measured wall temperature was prescribed in the simulation and the modeling setup was shown to retrieve the impact of heat losses on the studied turbulent flame. The objective of the present study is to estimate the wall heat losses without prior experimental knowledge, which translates into predicting accurately the wall temperature fields. Doing so paves the way to fully predictive simulations to determine structure heat loads and their feed-back effects on the flame.

As shown later, the predicted wall temperature field is close to the experimental one. The flame shape (not shown) and velocity profiles (Fig. 6) are then very similar to the ones obtained by imposing the measured wall temperature in the stand-alone reactive LES described in [24]. The next comparison with experimental measurements focuses on wall temperature.

The different mesh size and number of cores for each solver 

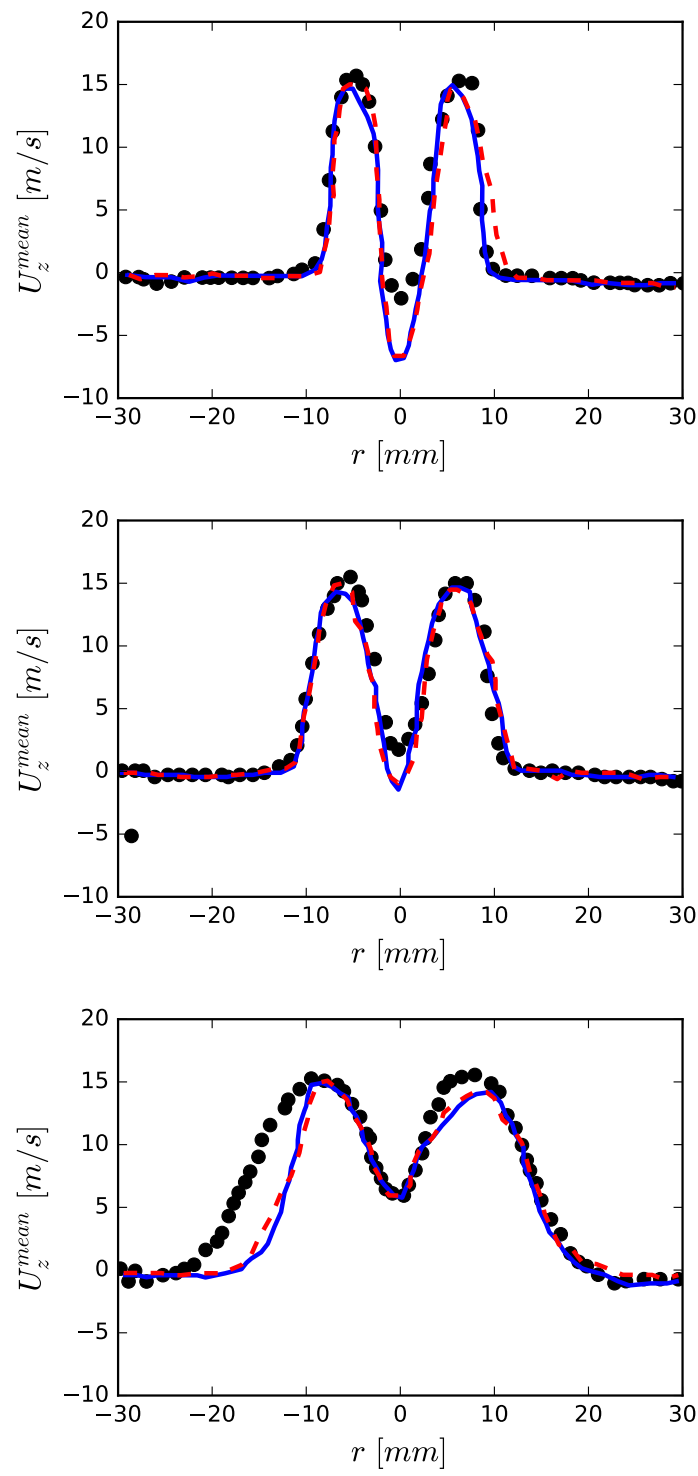

FIGURE 6. Radial profiles of mean longitudinal velocity at different heights (top: $5 \mathrm{~mm}$, middle: $10 \mathrm{~mm}$, botom: $25 \mathrm{~mm}$ ) in the combustor. Symbols: Experimental data [24]. Plain blue line: Numerical results from [24] for the stand-alone LES with imposed wall temperature. Dashed red line: Numerical results of the coupled simulation CASEFWR.

in both simulations are given in Tab. 1. For CASE-FW, the total computational cost is $350 \mathrm{k}$ hours on a Bull cluster equipped with Intel E5-2690 processors, while for CASE-FWR the cost is of approximatively $1 \mathrm{M}$ hours. The simulation of CASE-FWR was initiated with the final solution of CASE-FW. In terms of characteristic time scale of the combustor $\tau=H / U=18 \mathrm{~ms}$ (where $U$ is the bulk velocity in the injector), the sampling used for statis- tics computation is $10 \tau$ in CASE-FW and $0.6 \tau$ in CASE-FWR.

An example of the self-adaptive coupling time step computed in CASE-FW is presented in Fig. 7. The chosen error tolerance for the numerical integration is taken as $\eta=5 \%$. The obtained coupling time step has a mean value of approximatively 9 times the flow solver time step. This value is one order of magnitude below the stability limit of the coupling algorithm between the flow solver and the heat transfer solver. The advantage of the self-adaptative coupling time step enables not to $a$ priori fix this parameter. A similar methodology for the coupling with thermal radiation remains to be developed.

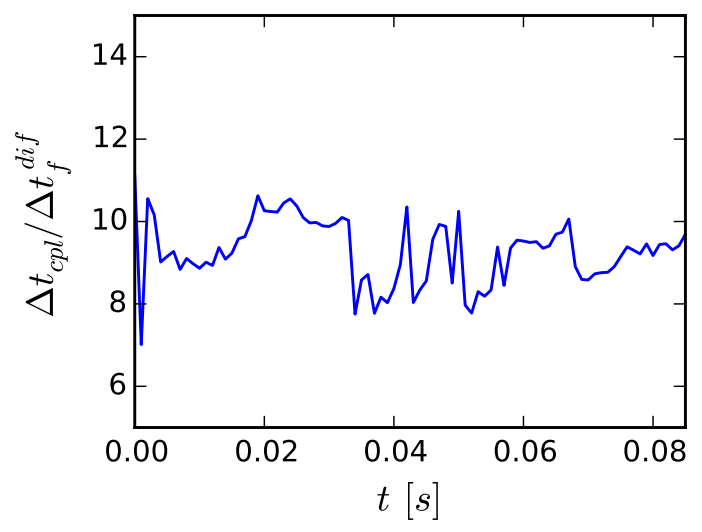

FIGURE 7. Temporal evolution of the self-adaptive coupling time step scaled by the flow solver diffusive time step, for flow-wall coupling (CASE-FW), with time origin taken at the begining of the run. Error tolerance is set to $\eta=5 \%$ for the HCND control algorithm.

\section{Wall temperature predictions}

The computed reactive flow is shown in Fig. 8. It is similar for both studied cases. As seen on the mean velocity field, the swirled injected flow generates a central recirculation zone as well as external ones. The zone A is located at the bottom of the chamber while the second external recirculation zone (B) is much longer. The extent of recirculation $B$ is roughly three fourth of the chamber height. A large volume of cooled burnt gases recirculates then towards the flame which is compact in respect to the chamber's size. As seen on the progress variable reaction rate, the dilution of the flame with such cold burnt gases damps the reaction zone in the swirled-flow outer shear layer. This effect can be accounted for thanks to the retained combustion model. Close to the combustor centerline, the burnt gases temperature is close to the adiabatic one just downstream the turbulent flame. Then, the hotter gases emit radiative energy (when radiation is considered) and mixes with the recirculating colder gases. 


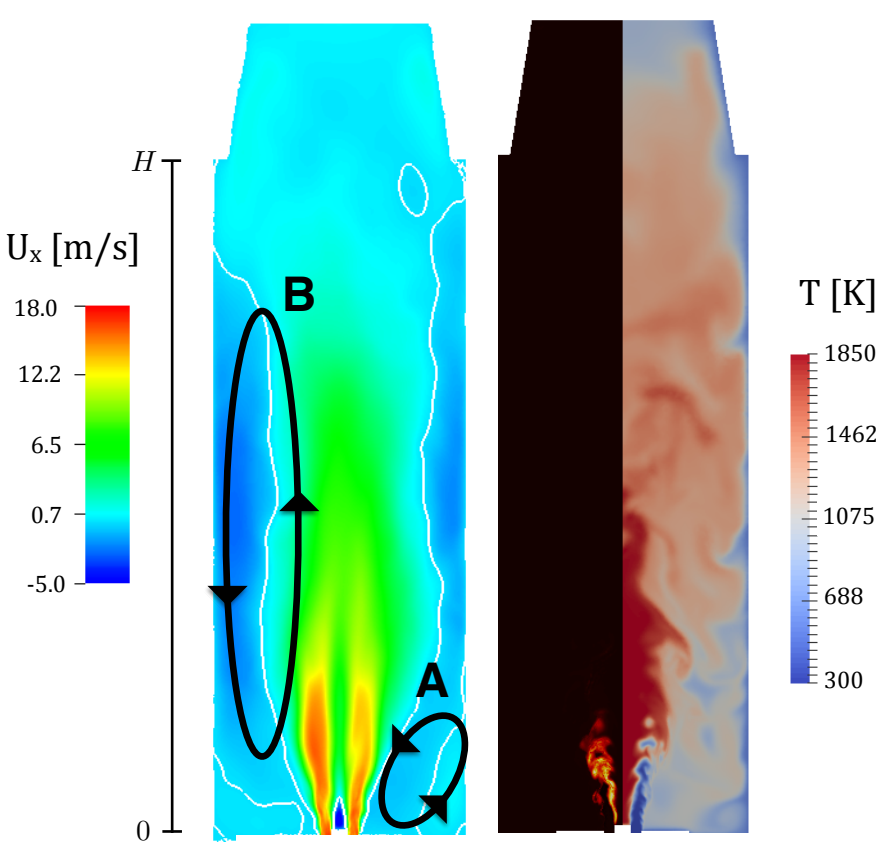

FIGURE 8. Visualization of fields on the center plane for CASEFWR. Left: Mean longitudinal velocity with the recirculation zones highlighted by the white iso-contour $U_{x}=0$. Right: Instantaneous progress variable reaction rate (left half-domain) and temperature (right half-domain)

The large recirculating zone B prevents the direct contact of the hottest gases with the wall. The resulting wall temperature and conductive flux is shown in Fig. 9. The wall temperature and heat flux peak in the upper part of the recirculation B. Below, as the burnt gases gets colder, the wall temperature decreases correspondingly. Finally, in the lowest zone, burnt gases are the coldest. This is accentuated by the slow recirculation zone A characterized by a large residence time and by the increased external heat transfer coefficient (Eq. 2) close to the chamber basis.

LIP measurements of temperature (in the dotted white zone in Fig. 9) from [24] are compared to the computed fields in Fig. 10. Such LIP measurements are less invasive than arrays of thermocouples and are characterized by a $1 \%$ accuracy [44]. Without accounting for radiation, CASE-FW (middle figure) already provides a good agreement with the experimental values with a maximal local error of approximatively $10 \%$. This level of agreement indicates that the radiation is not strongly significant in this configuration of moderate size in atmospheric pressure conditions. The similar shape of iso-lines shows that the simulated reactive flow and its non-uniformities are well predicted (see [24]).

When radiation from burnt gases and quartz walls is taken into account, CASE-FWR (bottom of Fig. 10) shows numeri-

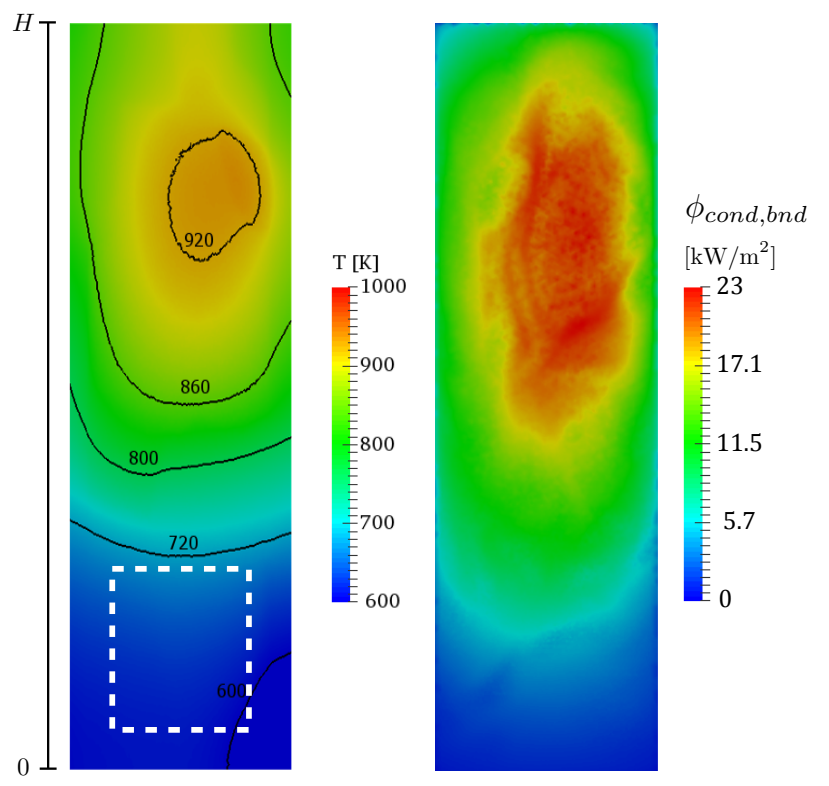

FIGURE 9. Left: Quartz mean wall temperature predicted in CASEFW. The doted white rectangle represents the zone of LIP measurements. Right: Corresponding mean wall conductive flux

cal predictions which are noticeably improved with a maximal local error of about 3\%. The previous underestimation of the wall temperature is then due to the neglected radiative effects. The observed level of agreement is truly impressive and has been achieved thanks to the derived high-fidelity multiphysics framework.

\section{Analysis of radiative effects}

Snapshots of a temperature field and the corresponding radiative power are presented in Fig. 11. The local radiative power is mode of two components: $P^{r a d}=P_{a}^{r a d}-P_{e}^{r a d}$ where $P_{a}^{r a d}$ and $P_{e}^{r a d}$ are the absorbed and emitted radiative power, respectively. The middle subfigure only shows the emitted radiative power $\left(-P_{e}^{r a d}\right.$ is plotted) which is showed to be larger in magnitude than the actual one (bottom figure) accounting for both emission and absorption. This difference outlines that an optically thin assumption that would neglect absorption phenomena for all the spectrum wavelength is here wrong and that the detailed radiative transfer equation must be solved.

The difference of mean gaseous temperature for cases CASE-FW and CASE-FWR is shown in the center plane in Fig. 12. The temperature maximum remains the same because the sudden temperature increase through the flame front is only marginally impacted by radiation. In the rest of the chamber, the radiative energy transfer homogenizes the temperature differences as also noticed in multi-physics simulations of a heli- 

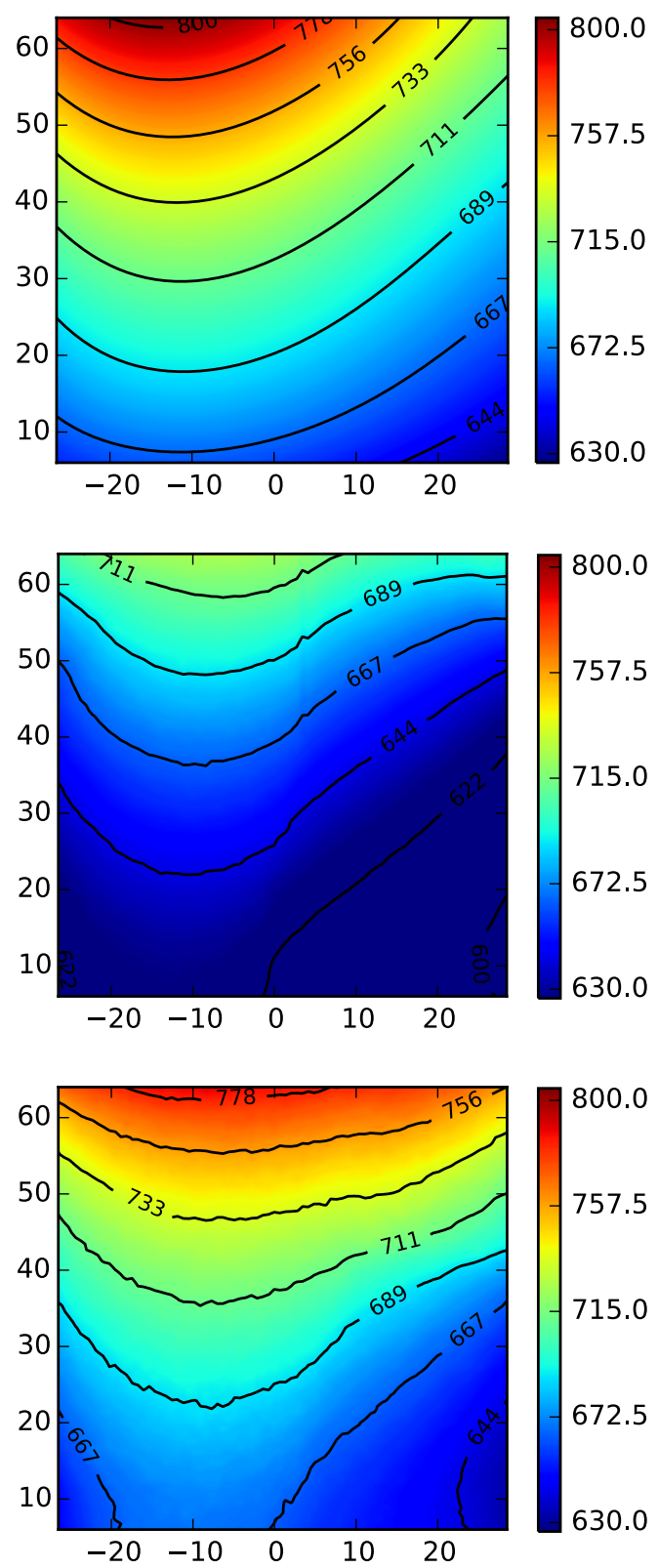

FIGURE 10. Wall temperature (in Kelvin) over the measurements zone: $y \in[-24.5,26.5], z \in[6,64]$, lengths in mm. Top: experimentally measured temperature values [24]. Middle: numerically computed wall temperature for CASE-FW. Bottom: numerically computed wall temperature for CASE-FWR.

copter chamber [6]. Hot burnt gases downstream the flame are seen to be colder when radiation is taken into account as seen with the noticeable difference for the $T=1400 \mathrm{~K}$ iso-line. On the other hand, the cold burnt gases at the bottom of the chamber
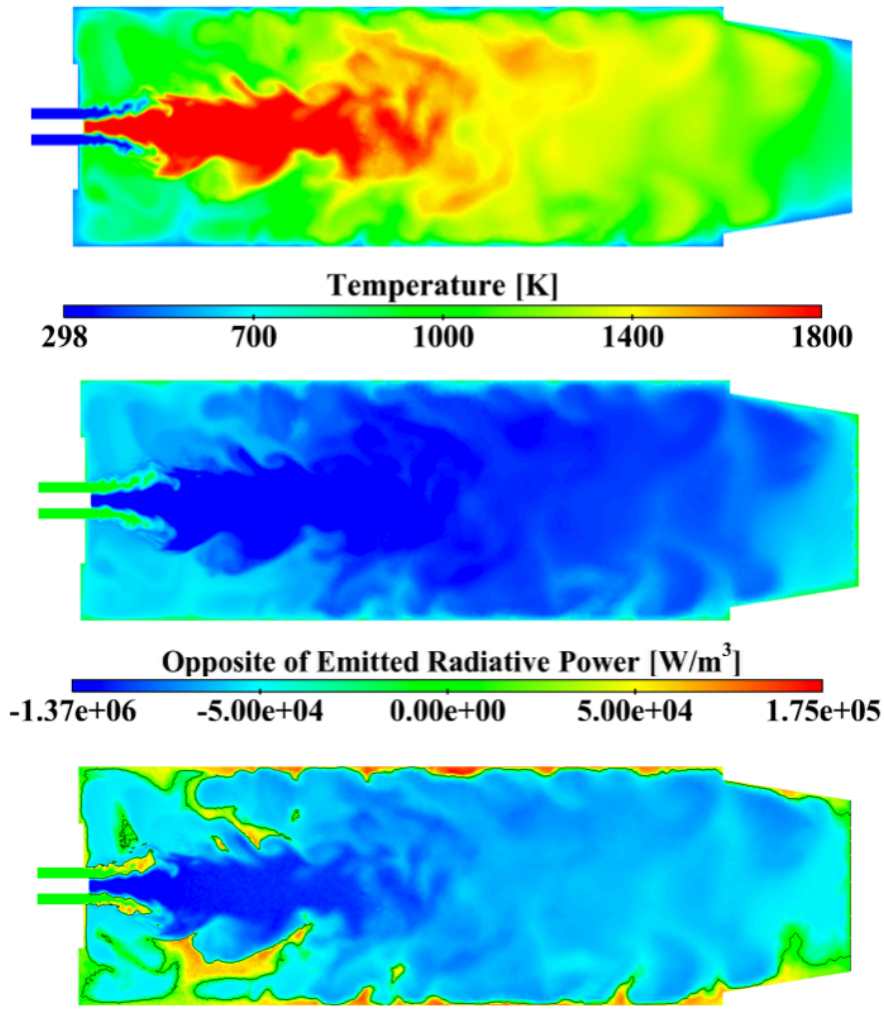

Radiative Power $\left[\mathrm{W} / \mathrm{m}^{3}\right]$

$\begin{array}{lllll}-1.37 \mathrm{e}+06 & -5.00 \mathrm{e}+04 & 0.00 \mathrm{e}+00 & 5.00 \mathrm{e}+04 & 1.75 \mathrm{e}+05\end{array}$

FIGURE 11. Top: Instantaneous temperature field on the center plane. Middle: Radiative power $-P_{e}^{r a d}$ (emission only). Bottom: Radiative power $P^{r a d}=P_{a}^{r a d}-P_{e}^{r a d}$ with emission and absorption accounted for.

are hotter for CASE-FWR because of the radiation absorbed by the walls which yields a higher wall temperature (seen previously in Fig. 10). The $T=1400 \mathrm{~K}$ iso-line which is more irregular in CASE-FWR compared to CASE-FW outlines that CASE-FWR is not as well statistically converged as CASE-FW. This is also noticeable in the wall conductive flux shown in Fig. 13. Getting smoother converged fields would have required an additional 1 or 2 million cpu hours consumption which could not be afforded.

The resulting wall radiative and conductive flux for CASEFWR are presented in Fig. 13. The wall radiative flux is seen to be of the same order of magnitude as the wall conductive flux, also seen in [6]. The ratio of wall-integrated (quartz walls only) 
conductive flux and total flux,

$$
\frac{\int_{w} \phi_{c o n d, b n d} d S}{\int_{w}\left(\phi_{c o n d, b n d} d S+\int_{w} \phi_{\text {rad }, \text { bnd }}\right) d S}
$$

leads to a global value of 0.53 . Estimating correctly the heat losses to the walls then requires to describe the radiative energy transfer. This conclusion seems contradictory to the relatively fair results obtained by CASE-FW to predict the wall temperature.

Let us explain this: Thermal radiation is an additional energy transfer mechanism that attenuate temperature differences between gas cells and also between the gas temperature and the wall temperature. Hence, when radiation is included, it is expected that the walls become hotter (see Fig. 10) while the burnt gases become cooler (see Fig. 12). After the thermal transient, the reduced temperature difference between the burnt gases and the walls induce a reduced wall conductive flux. Indeed, comparing the wall conductive flux for case FW (Fig. 9 right) and FWR (Fig. 13 bottom) shows that the wall flux is roughly halved when considering radiation. In case FWR, the reduced wall conductive flux is compensated by an additional contribution from the wall radiative flux. This feed-back loop of radiative transfer on the wall conductive flux explains why the total wall fluxes in the case FWR is not simply the conductive flux from the case FW with an additional contribution due to the radiation.

What remains surprising is the fact that the compensation from this feed-back loop lead roughly to the same wall temperature although the nature of the wall fluxes in the case FWR is so different. This is because, in the studied configuration, the CASE-FW conductive heat flux, which is overestimated compared to reality, surprisingly roughly accounts for the total wall heat flux (radiative and conductive) in case FWR.

This effect is clearly seen in the global energy budget of the combustor, expressed as a macroscopic balance of sensible enthalpy:

$$
\begin{array}{r}
\underbrace{\int_{\text {outlet }} \rho u h_{S} d S}_{I} \underbrace{-\int_{\text {inlet }} \rho u h_{S} d S}_{I I}+\underbrace{\int_{\text {walls }} \phi_{\text {cond }, \text { bnd }} d S}_{I I I} \\
+\underbrace{\int_{\text {walls }} \phi_{\text {rad } \text {,bnd }} d S}_{I V} \underbrace{-\dot{\Omega}=0}_{V}=0
\end{array}
$$

The different terms are the outlet convective flux (I), the algebraic value of inlet convective flux (II), the integrated wall conductive (III) and radiative (IV when considered) fluxes, and the opposite of the integrated heat release rate $(\mathrm{V})$. The budgets for cases FW and FWR are presented in Fig. 14. The comparison shows that the volume integrated heat release rate is effectively equal
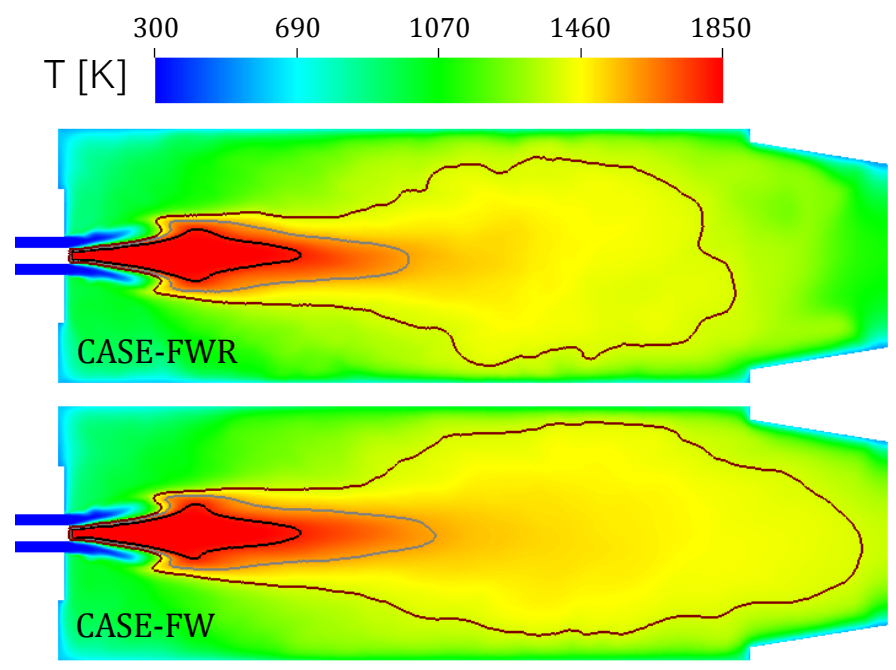

FIGURE 12. Mean temperature on center plane for CASE-FWR (top) and CASE-FW (bottom). Iso-lines are given for $\mathrm{T}=1800 \mathrm{~K}$ (black plain line), $\mathrm{T}=1600 \mathrm{~K}$ (gray plain line) and $\mathrm{T}=1400 \mathrm{~K}$ (brown plain line).

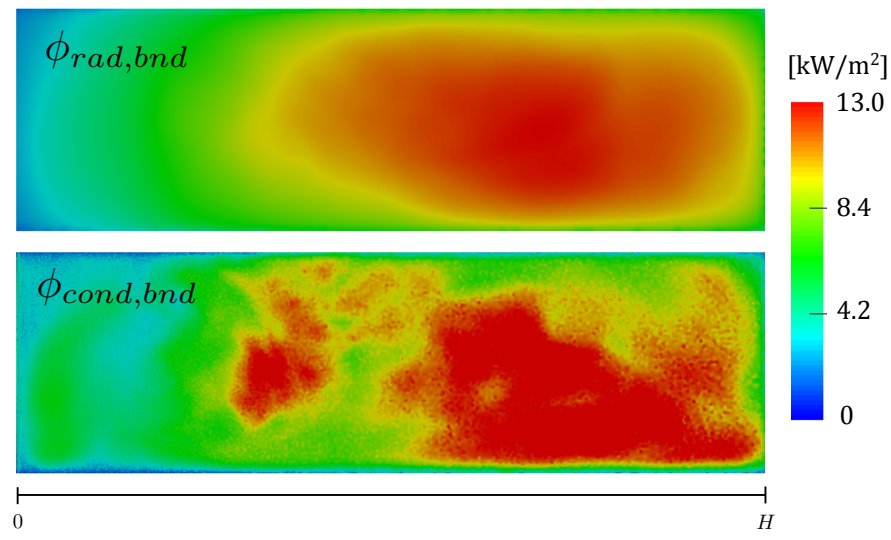

FIGURE 13. Wall radiative (top) and conductive (bottom) heat flux for CASE-FWR.

to $4 \mathrm{~kW}$ which is the burner theoretical power, showing that in both simulations the total amount of fuel is burnt. For CASE-FW around $35 \%$ of the produced thermal energy is lost through wall heat flux by conduction only, while for CASE-FWR it is nearly $50 \%$ for the sum of radiative and conductive contributions. For both cases, a substantial portion is then lost.

\section{Wall fluctuations}

The detailed unsteady multiphysics simulation enables to study the temporal variations in temperature and heat fluxes at the walls. The access to this unsteady thermal load on the com- 


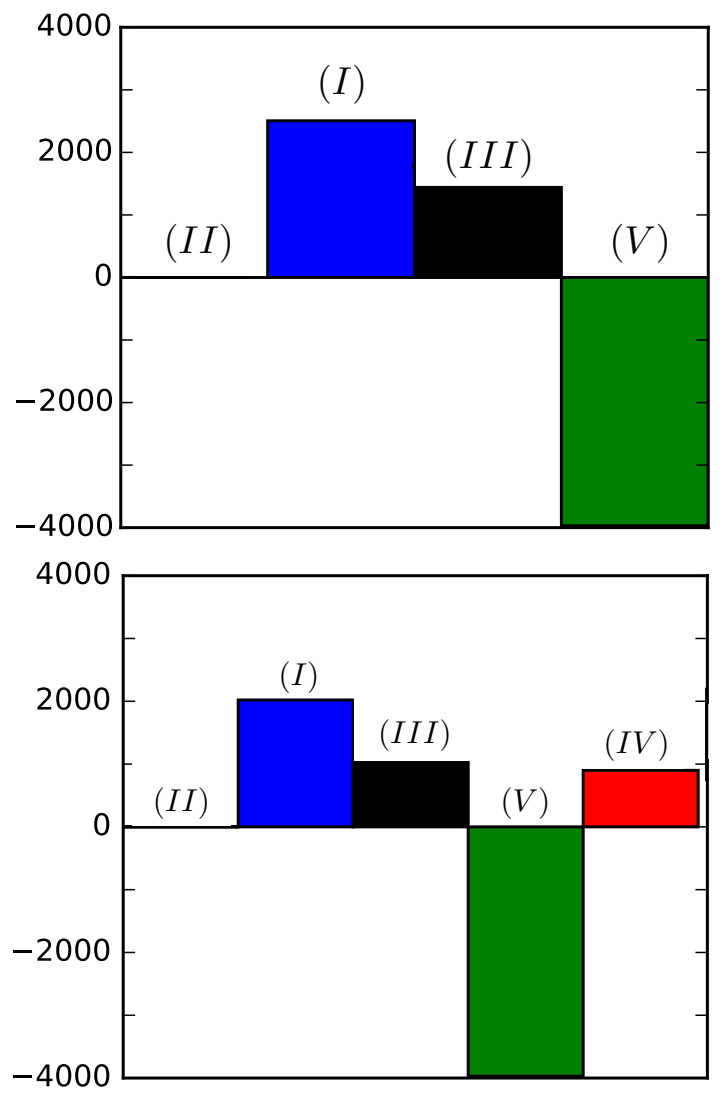

FIGURE 14. Energy budget of the combustor for both CASE-FW (top) and CASE-FWR (bottom). Plotted variables are the inlet sensible enthalpy flow rate (gray), outlet sensible enthalpy flow rate (blue), conductive wall heat flux (black), volume-integrated heat release rate (green) and wall radiative flux (red).

bustor walls is necessary to later assess the thermal fatigue.

Figure 15 shows root-mean-square fields in the experimentally studied window for CASE-FW and CASE-FWR. In CASE$\mathrm{FW}$, the fluctuations in wall temperature and wall conductive flux present a similar pattern, highlighting the correlation between both quantities as also deduced from Eq. 3. The average level of relative variation in the considered zone is approximatively $20 \%$ for the wall conductive flux and a little less than $1 \%$ for the wall temperature.

In CASE-FWR, the observed maximum value of wall temperature RMS is reduced but the field is more homogeneous, yielding a similar average level of relative variations $(\approx 1 \%)$. Similarly, with a roughly similar level of variations $(\approx 20 \%)$, the RMS in wall conductive flux is larger in CASE-FWR because of the increased steady wall conductive flux in the observed zone. Finally, the amplitude of variations in wall radiative flux is around $8 \%$. Compared to CASE-FW, no clear correlation ap-
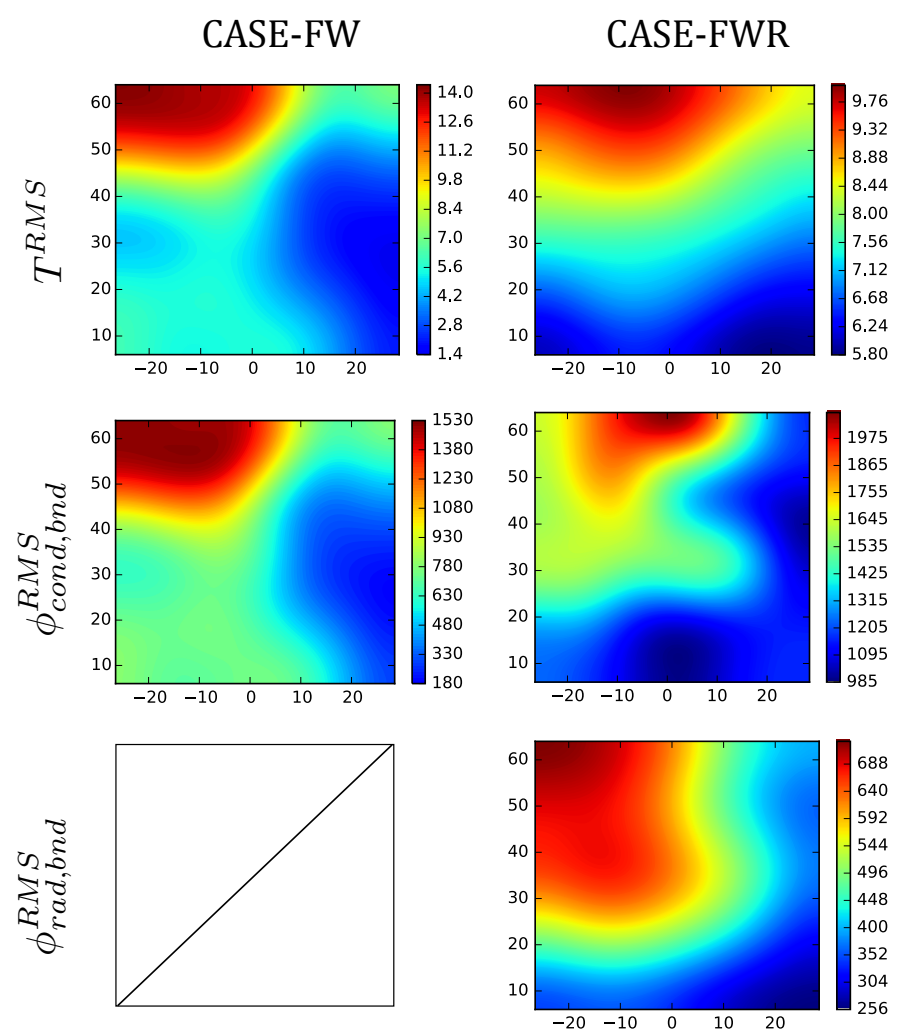

FIGURE 15. RMS of wall temperature [K] (top), wall conductive heat flux $\left[\mathrm{W} / \mathrm{m}^{2}\right]$ (middle) and wall radiative flux $\left[\mathrm{W} / \mathrm{m}^{2}\right]$ (bottom) for cases CASE-FW (left column) and CASE-FWR (right-column).

pear between the RMS in wall temperature and either of the wall fluxes. Further analysis will deal with frequency-domain correlation studies to better understand the relationship between these quantities.

\section{CONCLUSION}

This study presents a state-of-the-art multiphysics simulation framework combining i) large-eddy simulation, ii) an efficient Monte-Carlo solver with detailed radiative properties and controlled accuracy, and iii) a self-adaptive coupling procedure for conjugate heat transfer to compute accurately steady and unsteady components of the solid domain temperature. The resulting high-fidelity coupled simulation is applied to a confined premixed swirling flame under atmospheric pressure to predict the wall temperature measured experimentally by Laser Induced Phosphorescence. While always considering conjugate heat transfer, the coupled simulation is carried out with or without accounting for radiative energy transfer. Results yield a satisfactory agreement $(\approx 10 \%)$ without radiation which drops below $3 \%$ when detailed radiation is taken into account. The combined 
experimental characterization of combustion and heat transfer as carried out by $[18,19]$ in a confined turbulent flame is recent and similar future studies are necessary to assess further the accuracy of multi-physics simulations. A more complete validation will benefit for example from the measure of wall temperature on both sides along with the exhaust gases temperature. This would provide additional data in terms of wall total heat fluxes and the global amount of heat losses.

Analysis of the present simulation results shows that radiation strongly modifies the balance of the macroscopic energy budget in the combustor. Hence, concluding from the case without radiation that the wall conductive heat flux is dominant over the radiative one is plain wrong. The unsteadiness of wall temperature and heat fluxes is finally compared between both simulations, showing similarities and differences which shall need further analysis for a better understanding. The ability to determine such subtle unsteady heat loads on mechanical structures is very promising. Yet, additional experimental data on unsteadiness at combustors' walls are necessary to validate the estimated RMS fields.

Besides achieving accurate predictions, one of the objective of such high-fidelity simulations is their comparison with simpler approaches and low-oder models. Because of their large computational cost, they are not affordable in a design optimization loop for example. The obtained reference results on a couple of operating conditions and/or different geometries can be used to either calibrate other models or identify the origin of their lack of accuracy and possibly remedy it.

Future studies will also consider configurations closer to combustion chamber found in gas turbines where the combustor liner wall is made of a thin metal layer and includes cooling systems.

\section{ACKNOWLEDGEMENT}

This work was supported by the Air Liquide, CentraleSupélec and CNRS Chair on oxycombustion and heat transfer for energy and environment and by the OXYTEC project, grant ANR-12-CHIN-0001 of the French Agence Nationale de la Recherche. This work was granted access to the HPC resources of CINES under the allocation 2015-x20142b0164 made by GENCI. Vincent Moureau and Ghislain Lartigue from CORIA, and the SUCCESS scientific group are acknowledged for providing the YALES2 code. Thibault Guiberti is acknowledged for discussions concerning the experimental setup and measurements. We thank Benot Fiorina, Renaud Mercier and Adrien Chatelier for providing the initial numerical and modeling setup of the LES solver.

\section{REFERENCES}

[1] Moin, P., and Apte, S. V., 2006. "Large-eddy simulation of realistic gas turbine combustors". AIAA Journal, 44(4), pp. 698-708.

[2] Gicquel, L. Y. M., Staffelbach, G., and Poinsot, T., 2012. "Large Eddy Simulations of gaseous flames in gas turbine combustion chambers". Progress in Energy and Combustion Science, 38(6), pp. 782-817.

[3] Duchaine, F., Corpron, A., Pons, L., Moureau, V., Nicoud, F., and Poinsot, T., 2009. "Development and assessment of a coupled strategy for conjugate heat transfer with Large Eddy Simulation: Application to a cooled turbine blade". International Journal of Heat and Fluid Flow, 30(6), pp. 1129-1141.

[4] Duchaine, F., Maheu, N., Moureau, V., Balarac, G., and Moreau, S., 2013. "Large-eddy simulation and conjugate heat transfer around a low-mach turbine blade". Journal of Turbomachinery, 136(5), 10, pp. 051015-051015.

[5] Jaure, S., Duchaine, F., Staffelbach, G., and Gicquel, L., 2013. "Massively parallel conjugate heat transfer methods relying on large eddy simulation applied to an aeronautical combustor". Computational Science \& Discovery, 6(1), p. 015008.

[6] Berger, S., Richard, S., Duchaine, F., Staffelbach, G., and Gicquel, L. Y. M., 2016. "On the sensitivity of a helicopter combustor wall temperature to convective and radiative thermal loads". Applied Thermal Engineering, 103, 6, pp. 1450-1459.

[7] Mari, R., Cuenot, B., Rocchi, J.-P., Selle, L., and Duchaine, F., 2016. "Effect of pressure on hydrogen/oxygen coupled flame-wall interaction". Combustion and Flame, 168, 6, pp. 409-419.

[8] Jones, W. P., and Paul, M. C., 2005. "Combination of dom with les in a gas turbine combustor". International Journal of Engineering Science, 43(5-6), 3, pp. 379-397.

[9] dos Santos, R. G., Lecanu, M., Ducruix, S., Gicquel, O., Iacona, E., and Veynante, D., 2008. "Coupled large eddy simulations of turbulent combustion and radiative heat transfer". Combustion and Flame, 152(3), pp. 387-400.

[10] Poitou, D., Amaya, J., El Hafi, M., and Cuénot, B., 2012. "Analysis of the interaction between turbulent combustion and thermal radiation using unsteady coupled les/dom simulations". Combustion and Flame, 159(4), 4, pp. 16051618.

[11] Coelho, P. J., 2007. "Numerical simulation of the interaction between turbulence and radiation in reactive flows". Progress in Energy and Combustion Science, 33, pp. 311383.

[12] Coelho, P. J., 2012. “Turbulence-Radiation Interaction: From Theory to Application in Numerical Simulations". Journal of Heat Transfer-Transactions of the ASME, 134(3). 
[13] Soucasse, L., Riviere, P., and Soufiani, A., 2014. "Subgridscale model for radiative transfer in turbulent participating media". Journal of Computational Physics, 257(A), pp. 442-459.

[14] Gupta, A., Haworth, D., and Modest, M., 2013. "Turbulence-radiation interactions in large-eddy simulations of luminous and nonluminous nonpremixed flames". Proceedings of the Combustion Institute, 34(1), pp. 1281 1288.

[15] Lee, J. I., Hu, L.-w., Saha, P., and Kazimi, M. S., 2009. "Numerical analysis of thermal striping induced high cycle thermal fatigue in a mixing tee". Nuclear Engineering and Design, 239(5), pp. 833-839.

[16] Kuhn, S., Braillard, O., Ničeno, B., and Prasser, H.-M., 2010. "Computational study of conjugate heat transfer in t-junctions". Nuclear Engineering and Design, 240(6), pp. 1548-1557.

[17] Galpin, J., and Simoneau, J., 2011. "Large eddy simulation of a thermal mixing tee in order to assess the thermal fatigue". International Journal of Heat and Fluid Flow, 32(3), pp. 539-545.

[18] Guiberti, T. F., Durox, D., Zimmer, L., and Schuller, T., 2015. "Analysis of topology transitions of swirl flames interacting with the combustor side wall". Combustion and Flame, 162(11), pp. 4342-4357.

[19] Guiberti, T., Durox, D., Scouflaire, P., and Schuller, T., 2015. "Impact of heat loss and hydrogen enrichment on the shape of confined swirling flames". Proceedings of the Combustion Institute, 35(2), pp. 1385-1392.

[20] Nogenmyr, K. J., Cao, H. J., Chan, C. K., and Cheng, R. K., 2013. "Effects of confinement on premixed turbulent swirling flame using large eddy simulation". Combustion Theory and Modelling, 17(6), 12, pp. 1003-1019.

[21] Tay-Wo-Chong, L., Zellhuber, M., Komarek, T., Im, H. G., and Polifke, W., 2016. "Combined influence of strain and heat loss on turbulent premixed flame stabilization". Flow, Turbulence and Combustion, 97(1), pp. 263-294.

[22] Proch, F., and Kempf, A. M., 2015. "Modeling heat loss effects in the large eddy simulation of a model gas turbine combustor with premixed flamelet generated manifolds". Proceedings of the Combustion Institute, 35(3), pp. 33373345.

[23] Donini, A., Martin, S., Bastiaans, R., van Oijen, J., and de Goey, L., 2013. "Numerical simulations of a premixed turbulent confined jet flame using the flamelet generated manifold approach with heat loss inclusion". In ASME Turbo Expo 2013: Turbine Technical Conference and Exposition, no. V01AT04A024, American Society of Mechanical Engineers.

[24] Mercier, R., Guiberti, T., Chatelier, A., Durox, D., Gicquel, O., Darabiha, N., Schuller, T., and Fiorina, B., 2016. "Experimental and numerical investigation of the influence of thermal boundary conditions on premixed swirling flame stabilization". Combustion and Flame, 171, pp. 42-58.

[25] Fiorina, B., Veynante, D., and Candel, S., 2015. "Modeling combustion chemistry in large eddy simulation of turbulent flames". Flow, Turbulence and Combustion, 94(1), pp. 342.

[26] Ketelheun, A., Kuenne, G., and Janicka, J., 2013. "Heat transfer modeling in the context of large eddy simulation of premixed combustion with tabulated chemistry". Flow, Turbulence and Combustion, 91(4), pp. 867-893.

[27] Trisjono, P., Kleinheinz, K., Pitsch, H., and Kang, S., 2014. "Large eddy simulation of stratified and sheared flames of a premixed turbulent stratified flame burner using a flamelet model with heat loss". Flow, Turbulence and Combustion, 92(1), pp. 201-235.

[28] Mercier, R., Auzillon, P., Moureau, V., Darabiha, N., Gicquel, O., Veynante, D., and Fiorina, B., 2014. "Les modeling of the impact of heat losses and differential diffusion on turbulent stratified flame propagation: Application to the tu darmstadt stratified flame". Flow, turbulence and combustion, 93(2), pp. 349-381.

[29] Koren, C., Vicquelin, R., and Gicquel, O., 2016. "Selfadaptive coupling frequency for unsteady coupled conjugate heat transfer simulations". International Journal of Thermal Sciences (Submitted).

[30] Koren, C., Vicquelin, R., and Gicquel, O., 2017. "Simulation of conjugate heat transfer in a wall-impinging flame with a coupling time step controlling method". ASME Turbo EXPO 2017 (Submitted).

[31] Zhang, Y., Gicquel, O., and Taine, J., 2012. "Optimized emission-based reciprocity monte carlo method to speed up computation in complex systems". International Journal of Heat and Mass Transfer, 55(25), pp. 8172-8177.

[32] Moureau, V., Domingo, P., and Vervisch, L., 2011. "Design of a massively parallel cfd code for complex geometries". Comptes Rendus Mecanique, 339(2-3), pp. 141-148.

[33] Malandain, M., Maheu, N., and Moureau, V., 2013. “Optimization of the deflated conjugate gradient algorithm for the solving of elliptic equations on massively parallel machines". Journal of Computational Physics, 238, pp. 3247.

[34] Fiorina, B., Vicquelin, R., Auzillon, P., Darabiha, N., Gicquel, O., and Veynante, D., 2010. "A filtered tabulated chemistry model for les of premixed combustion". Combustion and Flame, 157(3), pp. 465-475.

[35] Auzillon, P., Gicquel, O., Darabiha, N., Veynante, D., and Fiorina, B., 2012. "A filtered tabulated chemistry model for les of stratified flames". Combustion and Flame, 159(8), pp. 2704-2717.

[36] Charlette, F., Meneveau, C., and Veynante, D., 2002. "A power-law flame wrinkling model for les of premixed turbulent combustion, part i: non-dynamic formulation". 
Combustion and Flame, 131(1/2), pp. 159-180.

[37] Fiorina, B., Mercier, R., Kuenne, G., Ketelheun, A., Avdić, A., Janicka, J., Geyer, D., Dreizler, A., Alenius, E., Duwig, C., et al., 2015. "Challenging modeling strategies for les of non-adiabatic turbulent stratified combustion". Combustion and Flame, 162(11), pp. 4264-4282.

[38] Taine, J., and Soufiani, A., 1999. “Gas $\{$ IR $\}$ radiative properties: From spectroscopic data to approximate models". Vol. 33 of Advances in Heat Transfer. Elsevier, pp. 295 414.

[39] Tesse, L., Dupoirieux, F., Zamuner, B., and Taine, J., 2002. "Radiative transfer in real gases using reciprocal and forward Monte Carlo methods and a correlated-k approach". International Journal of Heat and Mass Transfer, 45(13), pp. 2797-2814.

[40] Zhang, Y., Vicquelin, R., Gicquel, O., and Taine, J., 2013. "Physical study of radiation effects on the boundary layer structure in a turbulent channel flow". International Journal of Heat and Mass Transfer, 61, pp. 654-666.

[41] Zhang, Y. F., Vicquelin, R., Gicquel, O., and Taine, J., 2013. "A wall model for les accounting for radiation effects". International Journal of Heat and Mass Transfer, 67(0), 12, pp. 712-723.

[42] Vicquelin, R., Zhang, Y. F., Gicquel, O., and Taine, J., 2014. "Effects of radiation in turbulent channel flow: analysis of coupled direct numerical simulations". Journal of Fluid Mechanics, 753, 8, pp. 360-401.

[43] Buis, S., Piacentini, A., and Déclat, D., 2006. "Palm: a computational framework for assembling highperformance computing applications". Concurrency and Computation: Practice and Experience, 18(2), pp. 231245.

[44] Brübach, J., Pflitsch, C., Dreizler, A., and Atakan, B., 2013. "On surface temperature measurements with thermographic phosphors: A review". Progress in Energy and Combustion Science, 39(1), 2, pp. 37-60. 